\title{
Pengaruh Metode Resiprokal Terhadap Hasil Belajar Shooting Permainan Sepak Bola Siswa Kelas XI SMA Negeri Megang Sakti
}

\author{
Randa Sholihin', Hengki Kumbara², Zulpikar Ilham ${ }^{3}$ \\ ${ }^{1,2}$ Fakultas Keguruan dan Ilmu Pendidikan, Universitas PGRI Palembang, ${ }^{3}$ Fakultas Ilmu \\ Keolahragaan Universitas Negeri Medan \\ randa.solihin69@gmail.com, zulpikar_ilham@yahoo.com
}

\begin{abstract}
Abstrak: Tujuan dalam penelitian ini untuk mengetahui ada pengaruh metode resiprokal terhadap hasil belajar permainan sepak bola siswa kelas XI SMA Negeri Megang Sakti. Penggunaan metode dalam penelitian adalah metode eksperimen dengan jenis ne group desain pretest postest. Jumlah sampel yaitu 33 orang siswa kelas XI IPA 2. Teknik pengumpulan data penelitian menggunakan tes evaluasi hasil belajar shooting. Hasil penelitian menunjukkan ada pengaruh metode resiprokal terhada hasil belajar shooting permainan sepak bola siswa kelas XI IPA 2 SMA Negeri Megang Sakti karena karena thitung besar dari $t_{\text {tabel }}(3,150>1,680)$.
\end{abstract}

Kata Kunci : Resiprokal, Shooting, Sepakbola

\section{The Effect of the Reciprocal Method on the Learning Outcomes of Shooting in the Football Game of Class XI Students at SMA Negeri Megang Sakti}

Abstract: This study aims to determine the effect of the reciprocal method on learning outcomes of shooting in the soccer game of class XI students of SMA Negeri Megang Sakti. The method used is an experimental method with the type of one-group pretest-posttest design. The number of samples is 33 students of class XI MIPA 2. The data collection technique uses affective, psychomotor, and cognitive learning outcomes tests. Data analysis used paired sample t-test. The result of this study indicates that there is an effect of the reciprocal method on the learning outcomes of shooting soccer games for XI grade students of SMA Negeri Megang Sakti because t is greater than t table (3.150 > 1.680).

Keywords: Recipocal method, Shooting, Soccer

\section{PENDAHULUAN}

Berdasarkan amanat undang-undang Nomor 3 tahun 2005, tentang Sistem Keolahragaan Nasional (SKN), bahwa olahraga dibagi berdasarkan tiga tujuan yaitu olahraga pendidikan, olahraga rekreasi dan olahraga prestasi. Ketiga jenis olahraga ini diatur dalam lembaga yang berbeda-beda dijalankan untuk mencapai tujuan tertentu sesuai dengan aturan teknis yang diinginkan, sehingga ketiga jenis ini dapat mencapai dan ikut serta dalam mewujudkan cita-cita pembangunan nasional yaitu mewujudkan manusia Indonesia seutuhnya. Salah satu tugas yang diemban dalam olahraga pendidikan adalah menjalankan sistem pendidikan nasional melalui kurikulum pendidikan jasmani.

Pendidikan jasmani, olahraga dan kesehatan merupakan salah satu mata pelajaran wajib yang termasuk dalam kurikulum Sekolah Menengah Atas. Tujuan pendidikan jasmani adalah mengatur pertumbuhan fisik dan perkembangan mental siswa, hal ini sesuai dengan pernyataan (Junaedi \& Wisnu, 2015), berpendapat bahwa pendidikan jasmani merupaan bagian penting dari pendidikan menyeluruh dengan mengutamakan aktivitas jasmani dan pembinaan hidup sehat untuk pertumbuhan dan perkembangan jasmani, mental, sosial dan emosional yang serasi, selaras dan seimbang. Hal ini menjadi penting untuk diajarkan guru mengingat kebutuhan pendidikan jasmani berpengaruh sangat besar dalam membangun tumbuh kembang peserta didik dilingkungannya. 
Pembelajaran pendidikan jasmani pada siswa sekolah menengah atas melibatkan banyak aktivitas didalamnya, misalnya aktivitas permainan, atletik, ketangkasan, beladiri, aquatik, dan aktivitas-aktivitas lainya, semua diarahkan untuk mencapai derajat afektif, kognitif dan psikomotorik dalam belajar. Aktivitas-aktivitas tersebut terbagi dalam beberapa cabang olahraga yang menjadi media belajar siswa disekolah. Salah satu aktivitas permainan dalam pembelajaran pendidikan jasmani di SMA yang wajib dipelari oleh peserta didik adalah permainan sepak bola.

Sepak bola merupakan permainan yang diajarkan dalam materi pelajaran pendidikan jasmani olahraga dan kesehatan pada siswa kelas XI Sekolah Menengah Atas. Permainan sepak bola adalah permainan yang sangat digemari oleh masyarakat termasuk siswa. Menurut Kumbara dkk (2018: 31) permainan sepak bola membuat semua kalangan menyukai tanpa memandang suku, ras, golongan dan agama. Teknik-teknik yang indah membuat permainan ini menjadi menarik. Permainan ini memiliki banyak teknik dasar, misalnya teknik passing, dribbling, heading dan shooting. Salah satu teknik yang digemari oleh siswa dalam bermain sepak bola adalah kemampuan shooting. Shooting bertujuan menciptakan gol dengan menendang bola sekeras mungkin menuju kearah gawang lawan.

Materi shooting dalam permainan sepak bola merupakan bagian dari teknik dasar sepsifik yang diajarkan pada siswa SMA. Dalam pembelajaran sepak bola di SMA Negeri 1 Megang Sakti, diketahui teknik dasar yang belum mampu dikuasai dengan benar oleh siswa adalah teknik dasar shooting. Teknik tergolong cukup rumit untuk dikuasai siswa, oleh karenya lebih dari $50 \%$ siswa belum tuntas hasil belaja karena tidak mencapai kriteria ketuntasan minimul pada angka 75 . Beberapa penyebab belum tuntasnya hasil belajar tersebut dikarenakan, a) guru tidak memainkan peranan siswa sebagai motor dalam belajar, b) penggunaan metode belajar yang belum memenuhi karakteristik keinginan siswa, c) pembelajaran terkesan satu arah, tidak ada timbal balik antara kekuasaan siswa dan guru dalam belajar.

Salah satu upaya yang harus dilakukan dalam mengatasi rendahnya kualitas hasil belajar di atas, dengan memberikan metode pembelajaran yang benar-benar mampu mengatasi permasalahan dalam belajar. Penggunaan metode resiprokal diharapkan dapat mengatasi rendahnya hasil belajar siswa dalam belajar shooting. Rahayu (2013: 154) manfaat penggunaan metode resiprokal dalam hasil belajar adalah pemberian umpan balik sesaat tanpa penundaan dan mempunyai pengaruh yang nyata pada proses pembelajaran peserta didik. Umpan balik disini dimaksudkan agar siswa terangsang dalam materi yang diajarkan. Siswa dituntu lebih aktif untuk menggali kemampuan, dominan dalam belajar, sehingga berpengaruh dengan hasil belajar shooting permainan sepak bola. Berdasarkan pemaparan permasalahan di atas, peneliti tertarik untuk melakukan penelitian yang berjudul pengaruh metode resiprokal terhadap haisl belajar shooting permainan sepak bola siswa kelas XI SMA Megang Sakti.

\section{METODE}

Penelitian ini dilaksanakan di SMA Negeri Megang Sakti Kabupaten Musi Rawas, Propinsi Sumatera Selatan. Waktu pelaksanaan penelitian yaitu pada bulan agustus 2021. Penggunaan metode dalam penelitian adalah metode eksperimen dengan jenis one-group desain pre-test post-test. Variabel dalam penelitian ini adalah metode pembelajaran resiprokal sebagai variabel bebas dan hasil belajar shooting permainan sepak bola sebagai variabel terikat. Populasi penelitian seluruh siswa kelas XI berjumlah 260 siswa sedangkan sampel penelitian berjumlah 33 orang siswa kelas XI IPA 2. Instrumen penelitian yaitu menggunakan tes evaluasi hasil belajar ranah kognitif, ranah afektif dan psikomotorik. Pengujian hipotesis dan analisis data dilakukan dengan uji paired sampel t test.

\section{HASIL DAN PEMBAHASAN}

Pengumpulan data dalam penelitian ini, didapat dari pelaksanaan tes evaluasi hasil belajar pada ranah kognitif, afektif dan psikomotorik baik tes awal dan tes akhir. Berikut pada tabel di bawah ini dapat dilihat data hasil belajar siswa dalam diagram batang pada gambar di bawah ini: 


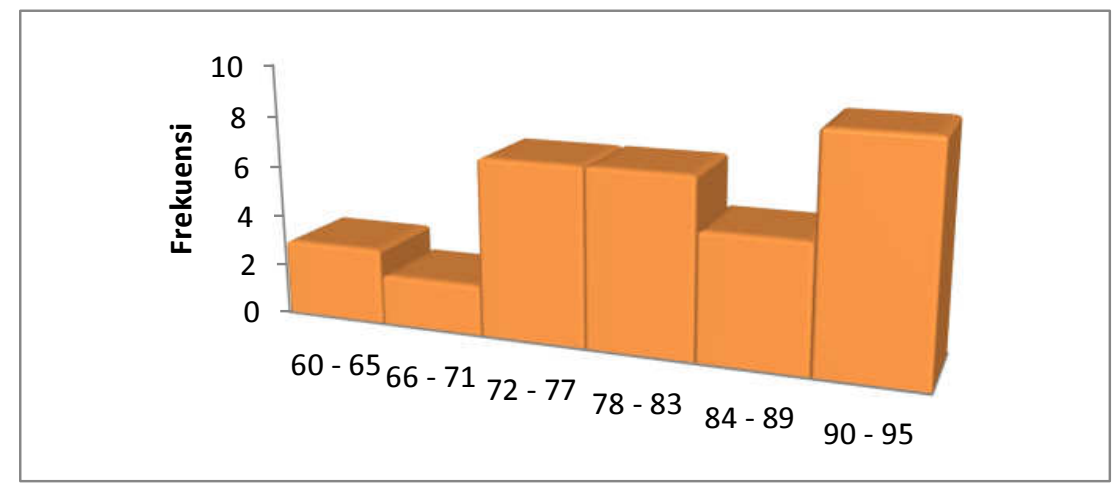

Gambar 1. Diagram Data Pretest

Berdasarkan grafik di atas, dapat interprestasikan bahwa siswa yang mencapai nilai hasil belajar shooting dengan interval 60-65 sebanyak 3 orang atau 9\%, nilai 66-67 sebanyak 2 orang atau 6\%, interval nilai 72-77 sebanyak 7 orang atau $21 \%$, nilai $78-83$ sebanyak 7 orang atau $21 \%$, nilai $84-89$ sebanyak 5 orang sebanyak $15 \%$ dan $90-95$ sebanya 9 orang atau $27 \%$. Adapun data tes akhir ditampilkan dalam diagram batang pada gambar di bawah ini:

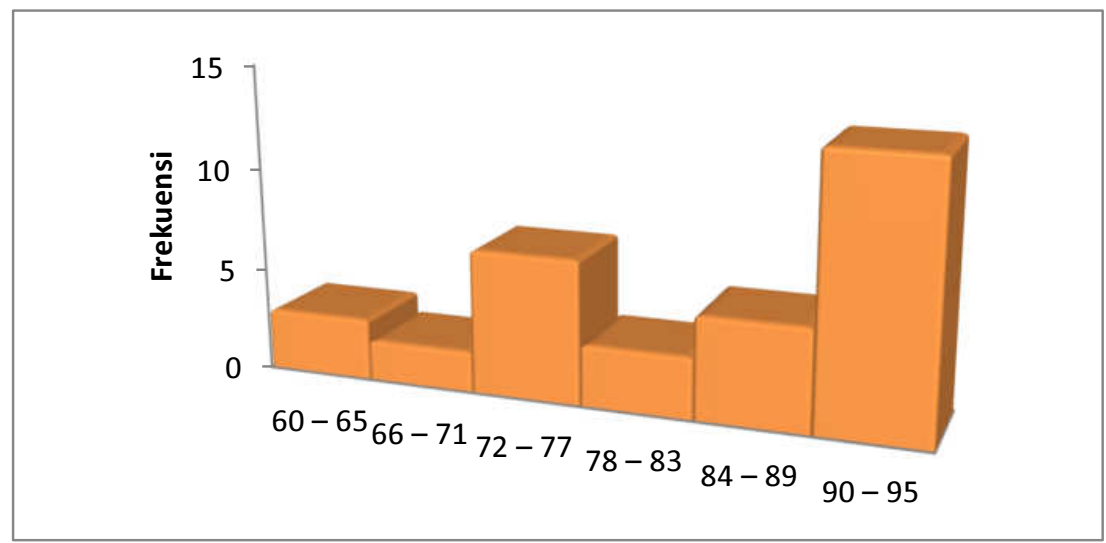

Gambar 2. Diagram Data Tes Akhir

Berdasarkan grafik di atas, dapat interprestasikan bahwa siswa yang mencapai nilai hasil belajar shooting dengan interval 60-65 sebanyak 3 orang atau 9\%, nilai 66-67 sebanyak 2 orang atau $6 \%$, interval nilai 72-77 sebanyak 7 orang atau 21\%, nilai 78-83 sebanyak 3 orang atau 9\%, nilai 84-89 sebanyak 5 orang sebanyak $15 \%$ dan $90-95$ sebanya 13 orang atau $39 \%$.

Pengujian normalitas dalam penelitian ini dilakukan dengan menguji data awal dan data akhir melalui uji kolmogrov smirnov pada SPSS 22 dengan taraf signifikan 0,05, untuk jelasnya hasil pengujian hipotesis dapat dilihat pada tabel di bawah ini:

Tabel 1. Uji Kolmogrov Smirnov

\begin{tabular}{cccc}
\hline \multirow{2}{*}{ Data } & \multicolumn{2}{c}{ Asymp Sig $>\mathbf{0 , 0 5}$} & Keterangan \\
\cline { 2 - 3 } & Asymp Sig & $\alpha$ & \\
\hline Pretest & 0,302 & 0,05 & Normal \\
\hline Postest & 0,86 & & \\
\hline
\end{tabular}


Berdasarkan tabel di atas dapat diinterprestasikan bahwa data berdistribusi normal baik data tes awal maupun tes akhir mengingat kedua data berada pada nilai sig besar dari 0,05. Dengan demikian data dinyatakan berdistribusi secara normal.

Uji Homogenitas dalam penelitian menggunakan pengujian one-way anava SPSS 22 pada tara signifikasi 0,05. Adapun hasil pengujian dapat dilihat pada tabel di bawah ini:

Tabel 2. Uji One Way Anava

\begin{tabular}{cccc}
\hline \multirow{2}{*}{ Data } & \multicolumn{2}{c}{ Sig $>\mathbf{0 , 0 5}$} & Keterangan \\
\cline { 2 - 3 } & Sig. & $\alpha$ & \\
\hline Pretest & 0,177 & 0,05 & Homogen \\
\hline Postest & & & \\
\hline
\end{tabular}

Berdasarkan tabel di atas dapat diinterprestasikan bahwa data berdistribusi homogen baik data tes awal maupun tes akhir mengingat kedua data berada pada nilai sig besar dari 0,05 . Dengan demikian data dinyatakan berdistribusi secara homogen. Pengujian hipotesis menggunakan uji paired sampel t-test. Hipotesis yang diajukan adalah terdapat pengaruh metode resiprokal terhadap hasil belajar shooting permainan epak bola siswa kelas XI SMA Negeri Megang Sakti. Adapun hasil pengujian dapat dilihat pada tabel di bawah ini:

Tabel 3. Uji Hipotesis

\begin{tabular}{c|c|c|c|c|c}
\multicolumn{1}{c}{ Set } & Mean & SD & t-hit & \multicolumn{1}{c}{ t-tab } & Keterangan \\
\hline Data Awal & 80,67 & 9,283 & \multirow{2}{*}{3,150} & 1,680 & Signifikan \\
\hline Data Akhir & 83,45 & 10,903 & & & \\
\hline
\end{tabular}

Berdasarkan tabel di atas dapat diinterprestasikan bahwa ada pengaruh yang signifikan dari metode resiprokal terhadap hasil belajar shooting permainan sepak bola siswa kelas XI SMA Negeri Megang Sakti karena $t_{\text {hitung }}$ besar $t_{\text {tabel }}(3,150>1,680)$.

Berdasarkan temuan hasil penelitian diperoleh rata-rata hasil belajar pada tes awal adalah 80,76 sedangkan rata-rata tes akhir hasil belajar 83,45. Berdasarkan hasil pengujian hipotesis diperoleh bahwa terdapat pengaruh model resiprokla terhadap hasil belajar shooting sepak bola siswa kelas XI SMA Negeri 2 Megang Sakti karena thitung besar $t_{\text {tabel }}(3,150>1,680)$. Hasil ini menandakan bahwa pembelajaran berjalan sesuai dengan yang diharapkan, dimana siswa benar-benar memanfaatkan metode resiprokal untuk menempah hasil belajar shooting permainan sepak bola.

Berdasarkan prosesnya pembelajaran yang dilakukan oleh guru dan siswa dengan menggunakan metode resiprokal untuk pembelajarna shooting berjalan sesuai yang diharapkan, siswa terlihat semangat dalam belajar, metode umpan balik membut perhatian belajar tidak hanya dominan pada guru tetapi lebih banyak menekankan pada kinerja murid. Oleh karena itu kualitas hasil belajar siswa menunjukan peningkatan rata-rata dari sebelumnya 80,76 meningkat mejadi 83,45 dengan pengujian hipotesis terjadi pengaruh yang signifikan.

Rahayu (2013: 154) manfaat penggunaan metode resiprokal dalam hasil belajar adalah pemberian umpan balik sesaat tanpa penundaan dan mempunyai pengaruh yang nyata pada proses pembelajaran peserta didik. Umpan balik disini dimaksudkan agar siswa terangsang dalam materi yang diajarkan. Materi shooting pada dasarnya adalah materi yang perlu diajarkan dengan spesifikasi yang dalam, mengingat materi ini cukup rumit untuk dipahami siswa. Ternyata materi ini sangat cocok jika diajarkan menggunakan metode resiprokal pada siswa SMA Negeri Megang Sakti.

Beberapa kajian terdahul yang relevan mendukung hasil penelitian pernah dilakukan oleh Saputra, Yuanita, \& Walton (2020). Penelitian ini menunjukan hasil terdapat pengaruh metode belajar resiprokal terhadap hasil belajar menendang dengan kaki bagian dalam pada permainan sepak bola 
siswa kelas X MAN 1 Pangkal Pinang karena thitung besar dari tabel $(4,102>1,701)$. Penelitian selanjutnya dilakukan oleh Syaleh, M. (2017) penelitian ini memperoleh hasil penerapan gaya mengajar resiprokal untuk meningkatkan hasil belajar gaya bebas pada mahasiswa sekolah tinggi olahraga dan kesehatan (STOK) Bina Guna. Besarnya persentase peningkatan adalah 72,12\%.

\section{SIMPULAN}

Berdasarkan temuan hasil penelitian maka dapat disimpulkan bahwa terdapat pengaruh yang signifikan dari metode resiprokal terhadap hasil belajar shooting permainan sepak bola siswa kelas XI SMA Negeri Megang Sakti karena $t_{\text {hitung }}$ besar $t_{\text {tabel }}(3,150>1,680)$.

\section{DAFTAR PUSTAKA}

Junaedi, A., \& Wisnu, H. (2015). Survei Tingkat Kemajuan Pendidikan Jasmani, Olahraga dan Kesehatan di SMK dan MA Negeri se Kabupaten Gresik. Jurnal Pendidikan Olahraga dan Kesehatan. http://ejournal.unesa.ac.id/index.php/jurnal-pendidikan-jasmani/issue/archive

Junaidi, \& Yudiana, Y. (2016). Pengaruh Gaya Mengajar Resiprokal dalam Pembelajaran Permainan Bola Voli Terhadap Pengembangan Kreativitas Siswa. Jurnal Pendidkan Jasmani dan Olahraga

Kumbara, H. (2018). Perbedaan Variasi Latihan Juggling dan Rasio Koordinasi Mata-Kaki Terhadap Hasil Kontrol Bola dari Tendangan Jarak Jauh Sepak Bola. Jurnal Ilmu Keolahgaraan (Halaman Olahraga Nusantara), Vol 1. http://dx.doi.org/10.31851/hon.v1i1.1499

Rahayu, E. T. (2013). Strategi Pembelajaran Pendidikan Jasmani. Bandung: Alfabeta.

Saputra, F., Yuanita, \& Walton, P. E. (2020). Pengaruh Metode Pembelajaran Resiprokal terhadap Hasil Belajar Menendang Dengan Kaki Bagian Dalam Pada Permainan Sepak Bola Siswa Kelas X MAN1 Pangkalpinang. Jurnal Ilmu Pendidikan Jasmani Olahraga, Kesehatan dan Rekreasi, 39-42. https://doi.org/10.35438/sparta.v2i2.175

Syaleh, M. (2017). Penerapan Gaya Mengajar Resiprokal Terhadap Peningkatan Hasil Belajar Renang Gaya Bebas. Jurnal ilmia STOK Bina Guna Medan, 31 https://jurnal.stokbinaguna.ac.id/index.php/JSBG/search 